\title{
Bilateral Cerebral Hemorrhage in Herpes Simplex Encephalitis: Rare Occurrence
}

Sir,

The most frequent cause of sporadic encephalitis is herpes simplex encephalitis (HSE). ${ }^{[1]}$ It carries a mortality of $70 \%$ if left untreated. With the usage of acyclovir in the management of HSE and early diagnosis, the mortality rate has been reduced to $19 \% \cdot{ }^{[2]}$ Herpes simplex virus (HSV) causes hemorrhagic necrotizing encephalitis involving the frontal and medial temporal lobes. Petechial cortical hemorrhages have been reported in HSE; however, frank hematoma is rare. Bilateral cerebral hemorrhage in HSE has not been reported so far. Hereby, we report a patient who presented with febrile illness with altered level of consciousness. Brain magnetic resonance imaging (MRI) showed left parieto-occipital and right occipital hemorrhages. Cerebrospinal fluid (CSF) examination showed positive polymerase chain reaction (PCR) for HSV deoxyribonucleic acid (DNA).

A 71-year-old man was brought to the emergency department with the history of fever of 5 days duration, headache of 5 days, and altered level of consciousness of 1-day duration. Fever was moderate degree, intermittent, associated with chills. Headache was holocranial, throbbing, and intermittent lasting for 2-3 h, relieved with vomiting. There were no seizures, loose stools, or limb weakness. He lapsed into altered level of consciousness a day before admission. He became drowsy, irritable and was not recognizing family members. $\mathrm{He}$ was hypertensive on medication. Systemic examination was unremarkable. His vitals were pulse rate, 98 beats/min; blood pressure, 138/88 mmHg; respiratory rate, 26 breaths/ min. On neurological examination, he was drowsy, irritable, and agitated. He was not responding appropriately to verbal commands. Fundus examination showed bilateral papilledema. Pupils were equal and reactive. Extraocular movements were full. There was no facial weakness. Motor examination showed normal tone and deep tendon reflexes. He was moving all his limbs. Plantar responses were mute. Complete hemogram showed raised total leukocyte count of 17,800 per $\mathrm{mm}^{3}$ with normal platelet counts. His serum creatinine was $2.1 \mathrm{mg} / \mathrm{dL}$. Hepatic and thyroid functions were normal. Serum electrolytes and coagulation parameters were normal. Brain MRI showed left parieto-occipital and right occipital hemorrhage. MR venography did not show dural venous sinus occlusion [Figures 1 and 2]. Electroencephalography showed bilateral posterior quadrant slowing of background rhythm in the theta range. CSF examination showed normal protein, glucose and 5 cells (lymphocytes). HSV-DNA was positive in CSF sample by PCR. He was started on renal adjusted dose of acyclovir (500 mg/day) and dexamethasone. There was improvement in his level of consciousness within 7 days. However, he had cortical blindness. He was discharged after 2 weeks. There was mild improvement in his vision at follow-up at 1 month.

HSV enters the brain through the direct neuronal transmission from the peripheral site to the brain through the trigeminal or olfactory nerve. The usual manifestation of HSE is fever, headache, seizures, and change in mental status evolving over several days. Atypical manifestation includes intracerebral hemorrhage which has been reported mainly in infants and young children. Intracerebral hematoma in HSE in adults is rare. There are some reports of the occurrence of hematoma in HSE in the adults. The exact mechanism of hemorrhage in HSE is unclear. Vasculitis causing small vessel rupture and 

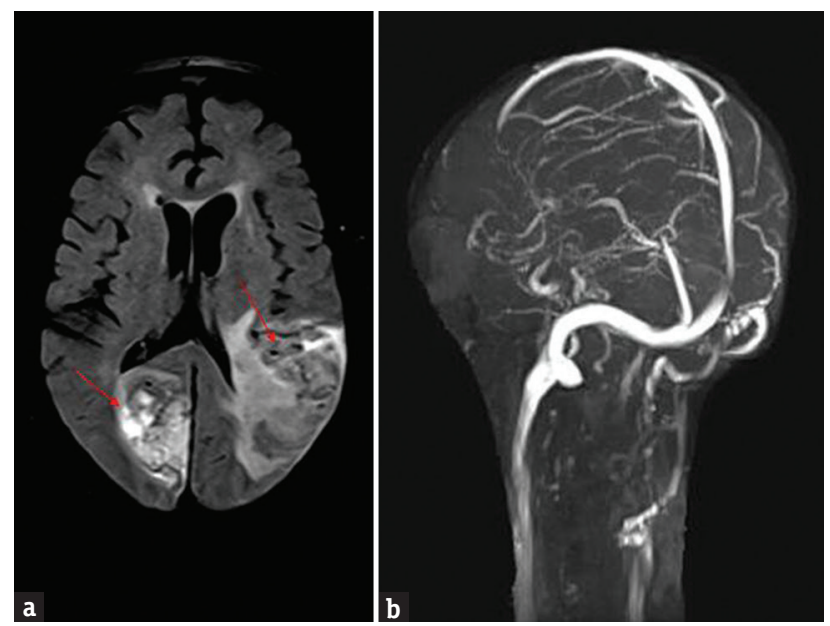

Figure 1: Brain magnetic resonance imaging fluid attenuated inversion recovery image axial view (a) showing hyperintensities in the right occipital and left parieto-occipital region (red arrows); magnetic resonance venography (b) is normal

transient hypertension due to raised intracranial pressure has been proposed for hemorrhage in HSE. ${ }^{[3]}$

Malik et al. reported the occurrence of large intracerebral hematoma in the temporal lobe in their patient with histopathologically proven HSE. ${ }^{[2]}$ Hiyama et al. reported an elderly woman with HSE who had temporal lobe hematoma that necessitated surgical decompression but ended fatally. ${ }^{[4]}$ Plantinga et al. reported a patient who developed temporoparietal hematoma within 1 week of admission. ${ }^{[5]}$ Biswas et al. reported a patient who had frontal and temporal lobe hematoma and was managed conservatively with good recovery. ${ }^{[6]}$ Argyriou et al. and Shelley et al. reported two young patients who developed medial temporal lobe hematoma after 10 and 15 days of admission, respectively, with good recovery. ${ }^{[7,8]}$ Similarly, Li and Sax, Fukushima et al., Takeuchi and Takasato, and Rodríguez-Sainz et al. reported patients with HSE who developed temporal lobe hematoma as late complication. ${ }^{[3,9-11]}$ The presenting manifestation of the patient reported by $\mathrm{Yu}$ et al. was temporal lobe hematoma without preceding fever. ${ }^{[12]}$

The intracerebral hematoma in the above-mentioned case reports involved the temporal lobe which is the typical area affected by the HSV. Our patient had bilateral cerebral hemorrhage involving right occipital and left parieto-occipital lobe. Venography did not reveal venous sinus occlusion. These sites have not been reported to be involved in HSE. Bilaterality of hemorrhage in HSE has not been reported so far.

The occurrence of intracerebral hematoma in adults with HSE is rare. The usual location of hematoma reported is medial temporal lobe and is unilateral. Our patient had bilateral cerebral hemorrhage involving parietal and occipital lobe which is unusual.

\section{Financial support and sponsorship}

Nil.

\section{Conflicts of interest}

There are no conflicts of interest.
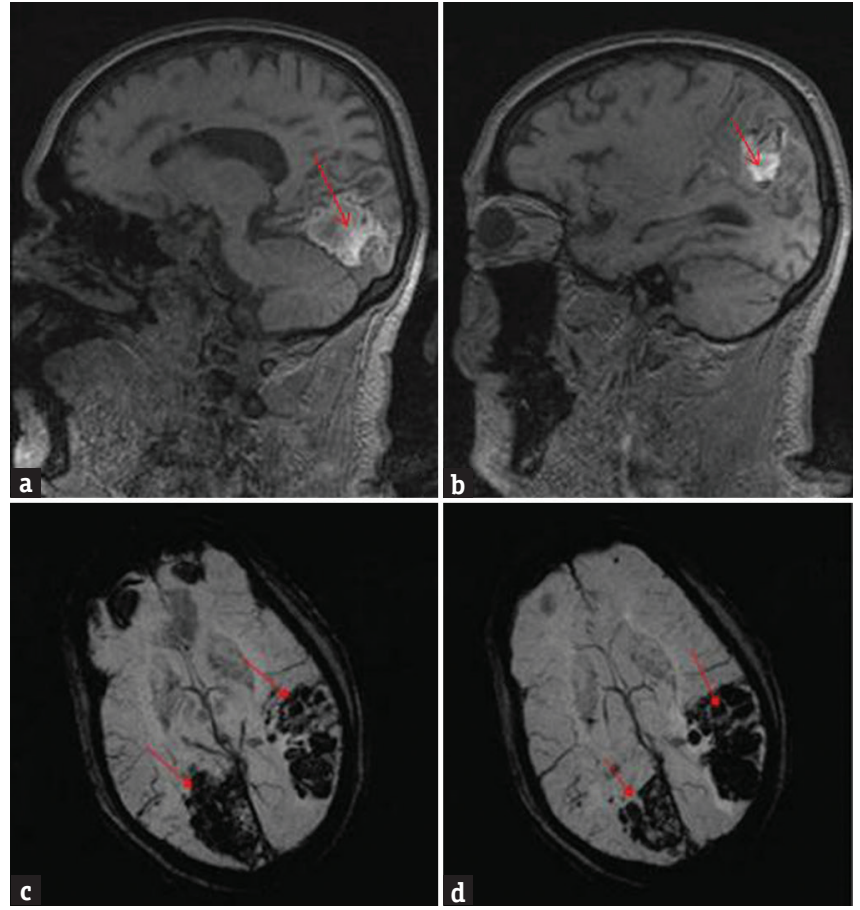

Figure 2: Brain magnetic resonance imaging T1-weighted image sagittal view ( $\mathrm{a}$ and $\mathrm{b}$ ) showing hyperintensities in the right occipital and left parieto-occipital region; $\mathrm{T} 2 *$ gradient-echo image axial view (c and d) showing blooming suggestive of hemorrhage in the right occipital and left parieto-occipital region (red arrows)

Rohan R. Mahale, Anish Mehta, Abhinandan K. Shankar, Abhishek Miryala, Purushottam Acharya, Rangasetty Srinivasa

Department of Neurology, M.S. Ramaiah Medical College and Hospital, Bengaluru, Karnataka, India

Address for correspondence: Dr. Rohan R. Mahale, Department of Neurology, M.S. Ramaiah Medical College and Hospital, Bengaluru - 560 054, Karnataka, India.

E-mail: rohanmahale83@gmail.com

\section{REFERENCES}

1. Whitley RJ, Kimberlin DW, Roizman B. Herpes simplex viruses. Clin Infect Dis 1998;26:541-53.

2. Malik A, Goyal M, Mishra NK, Gaikwad SB, Padma V. Intracerebral haematoma formation in herpes simplex encephalitis: A case report. Australas Radiol 1997;41:303-5.

3. Fukushima Y, Tsuchimochi H, Hashimoto M, Yubi T, Nakajima Y, Fukushima T, et al. A case of herpetic meningoencephalitis associated with massive intracerebral hemorrhage during acyclovir treatment: A rare complication. No Shinkei Geka 2010;38:171-6.

4. Hiyama H, Tanaka Y, Kawakami T, Matsuo S, Sawada T, Hori $\mathrm{T}$, et al. A case of fatal herpes encephalitis presenting massive cerebral hematoma. No Shinkei Geka 2001;29:271-6.

5. Plantinga EG, Vanneste JA. Mild herpes simplex encephalitis worsening despite acyclovir treatment. J Neurol 2001;248:237-8.

6. Biswas A, Das SK, Roy T, Dhibar T, Ghorai SP. Acute intracerebral haematoma - An unusual presentation of herpes simplex encephalitis. J Assoc Physicians India 2004;52:69-71.

7. Argyriou AA, Tsota I, Solomou E, Marangos M, Kalogeropoulou C, Petsas T, et al. Intracerebral haemorrhage as 
a rare complication of HSV-1 meningoencephalitis: Case report and review of the literature. Scand J Infect Dis 2006;38:63-6.

8. Shelley BP, Raniga SB, Al-Khabouri J. An unusual late complication of intracerebral haematoma in herpes encephalitis after successful acyclovir treatment. J Neurol Sci 2007;252:177-80.

9. Li JZ, Sax PE. HSV-1 encephalitis complicated by cerebral hemorrhage in an HIV-positive person. AIDS Read 2009;19:153-5.

10. Takeuchi S, Takasato Y. Herpes simplex virus encephalitis complicated by intracerebral hematoma. Neurol India 2011;59:594-6.

11. Rodríguez-Sainz A, Escalza-Cortina I, Guio-Carrión L, Matute-Nieves A, Gómez-Beldarrain M, Carbayo-Lozano G, et al. Intracerebral hematoma complicating herpes simplex encephalitis. Clin Neurol Neurosurg 2013;115:2041-5.

12. Yu W, Lee A, Welch B. Herpes simplex encephalitis presents as large temporal lobe haemorrhage. Neurol Cases 2014;1:12-5.
This is an open access article distributed under the terms of the Creative Commons Attribution-NonCommercial-ShareAlike 3.0 License, which allows others to remix, tweak, and build upon the work non-commercially, as long as the author is credited and the new creations are licensed under the identical terms.

\begin{tabular}{|l|l|}
\hline \multicolumn{2}{|c|}{ Access this article online } \\
\hline Quick Response Code: & Website: \\
\hline
\end{tabular}

How to cite this article: Mahale RR, Mehta A, Shankar AK, Miryala A, Acharya P, Srinivasa R. Bilateral cerebral hemorrhage in herpes simplex encephalitis: Rare occurrence. J Neurosci Rural Pract 2016;7:S128-30. 